
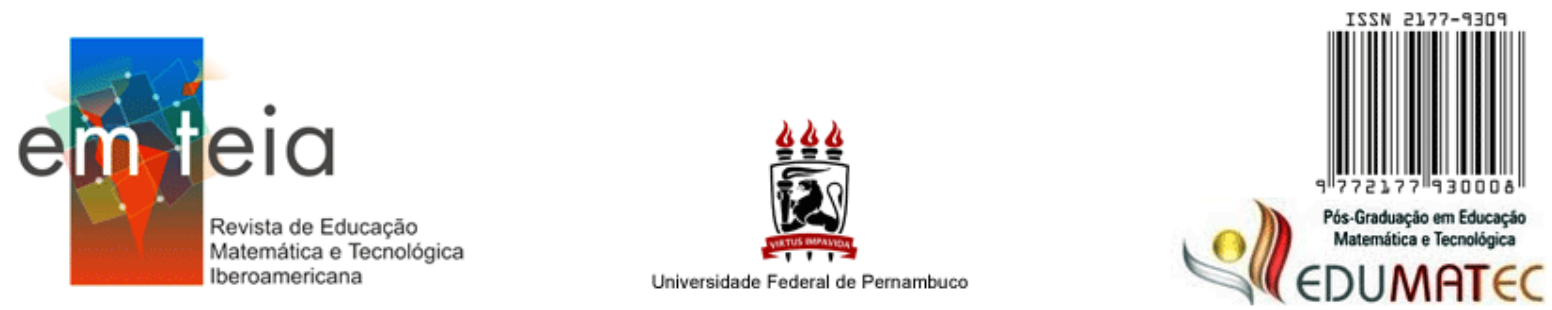

\title{
Álgebra Escolar na Contemporaneidade: uma discussão necessária
}

\begin{abstract}
Jadilson Ramos Almeida
jadilsonalmeida@hotmail.com

\section{Resumo}

Esse texto tem por objetivo realizar uma reflexão acerca da álgebra escolar na contemporaneidade. $\mathrm{Na}$ primeira seção do texto, temos uma tentativa de caracterização desse campo da matemática, que revelou assumir duas definições. Uma na qual a álgebra escolar é entendida como uma linguagem específica utilizada para representar valores, essencialmente desconhecidos, e outra em que a álgebra escolar é vista como uma maneira peculiar de pensar acerca de situações matemáticas. A partir de então, temos duas outras seções nesse texto. A primeira com uma discussão do ensino de álgebra com foco na linguagem algébrica e a segunda com uma reflexão acerca do ensino de álgebra com foco no desenvolvimento do pensamento algébrico. Concluímos nosso texto defendendo que o ensino de álgebra na educação básica deva ocorrer com foco no desenvolvimento do pensamento algébrico, em que os objetos algébricos e a linguagem utilizada para representa-los devam ser aprendidos pelos alunos de forma significativa.

Palavras-chave: Álgebra Escolar; Linguagem Algébrica; Pensamento Algébrico.
\end{abstract}

\section{School Algebra in Contemporaneity: A Necessary Discussion}

\begin{abstract}
This text aims to reflect on school algebra in contemporary times. In the first section of the text, we have an attempt to characterize this field of mathematics, which revealed two definitions. One in which school algebra is understood as a specific language used to represent values, essentially unknown, and another in which school algebra is seen as a peculiar way of thinking about mathematical situations. From then on, we have two other sections in this text. The first with a discussion of algebra teaching with a focus on algebraic language and the second with a reflection on the teaching of algebra with a focus on the development of algebraic thinking. We conclude our text by arguing that the teaching of algebra in basic education should occur with a focus on the development of algebraic thinking, in which algebraic objects and the language used to represent them should be learned by students in a meaningful way.
\end{abstract}

Keywords: School Algebra; Algebraic Language; Algebraic Thinking.

\section{Introdução}

Refletir a respeito de álgebra escolar não é uma tarefa fácil. Alguns autores discutem esse eixo da matemática levando em consideração sua linguagem, entendendo a álgebra como uma linguagem específica para representar, por exemplo, quantidades desconhecidas (BOOTH, 1995; USISKIN 1995). Outros, baseados em perspectivas atuais, defendem a 
álgebra como uma forma peculiar de pensar (KIERAN, 2007; KAPUT, 2008; RADFORD, 2011b).

Diante disso, surgiu a intenção de discutir a álgebra escolar de uma forma reflexiva. Nesse sentido, temos, nesse texto, o objetivo de realizar uma reflexão acerca da álgebra escolar na contemporaneidade. Para isso, dividimos nosso texto em três seções. A primeira com o propósito de nos aproximar de uma caracterização de álgebra escolar. Na segunda seção refletimos sobre o ensino da álgebra com foco na linguagem, e na terceira temos uma discussão sobre o ensino da álgebra com foco no pensamento algébrico. Por fim temos nossas considerações acerca do tema.

\section{Álgebra escolar: algumas características}

A álgebra escolar se caracteriza, principalmente, pela álgebra trabalhada na educação básica. Mas, o que é essa álgebra? Booth (1995) nos coloca que uma das diferenças mais marcantes entre "a aritmética e a álgebra é, obviamente, a utilização, nessa última, de letras para indicar valores” (p. 30). Apesar de letras aparecerem também em aritmética, essa autora lembra que os sentidos são bastantes diferentes. Por exemplo, a letra "m" "pode ser utilizada em aritmética para representar 'metros', mas não para representar o número de metros, como em álgebra" (p. 30).

Acreditamos que utilizar essa definição de álgebra ${ }^{1}$ é, a princípio, reduzi-la a uma linguagem, a linguagem simbólica algébrica, formada essencialmente por símbolos e letras para representar valores, muitas vezes desconhecidos. Entretanto, muitos pesquisadores na área de educação matemática, com foco na algébrica escolar, como Kieran (1992, 1996, 2004, 2007), Miguel, Fiorentini e Miorim (1992), Fiorentini, Miorim e Miguel (1993), Blanton e Kaput (2005), Arcavi (2005), Kaput (1999, 2008), Radford (2009, 2011b), dentre outros, defendem que a álgebra é muito mais que uma linguagem. É, essencialmente, uma forma de pensar. Portanto,

álgebra não é apenas um conjunto de procedimentos envolvendo os símbolos em forma de letra, mas consiste, também, na atividade de generalização e proporciona uma variedade de ferramentas para representar a generalidade das relações matemáticas, padrões e regras (e.g. Mason, 2005). Assim, a álgebra passou a ser encarada não apenas como uma técnica, mas também como uma forma de pensamento e raciocínio acerca de situações matemáticas (KIERAN, 2007, p. 5, tradução nossa, grifo nosso).

\footnotetext{
${ }^{1}$ Em muitos momentos desse texto estamos nos referindo à álgebra como sinônimo de álgebra escolar, pois acreditamos que a álgebra trabalhada na escola não pode ser tratada como uma não álgebra, ou como uma álgebra inferior. Talvez a álgebra da educação básica tenha, a princípio, objetos, linguagem e formalidade específica dessa fase de escolarização.
} 
Defendemos, nesse texto, essa ideia de álgebra escolar. Acreditamos que a álgebra se revela muito mais na maneira do sujeito pensar, em detrimento da linguagem utilizada para expressar esse pensamento. Para entender melhor essa definição de álgebra escolar, discutiremos, a seguir, dois exemplos.

Exemplo 1. A expressão " $7+5=12$ ", é álgebra ou aritmética?

Quem defende a definição de álgebra de Booth (1995) responderá a essa questão sem muita dificuldade, afirmando que essa expressão se relaciona à aritmética, por conter apenas operações numéricas. Porém, será isso mesmo? Para nós não é tão simples assim. Não é a maneira que a expressão é apresentada que diz se ela pertence ao domínio da álgebra ou da aritmética, mas o que o sujeito pensa sobre ela.

Nesse sentido, para nós, a resposta a essa questão é “depende". Depende de como o sujeito compreende essa expressão. Se ele entende o sinal de igual como uma simples ação para se chegar ao valor da adição "7 +5 ", isto é, o sinal de igualdade apresenta um significado operacional (KIERAN, 1981) correspondendo a uma ação a ser realizada, essa expressão estaria no campo da aritmética. Porém, se o sujeito consegue perceber que o sinal de igual significa que existe uma equivalência entre o termo antes da igualdade e o termo depois da igualdade, se ele entender que "7 +5 ” equivale a 12 , ou seja, é igual a 12 , essa expressão deixa de ser pensada pelo sujeito como uma expressão aritmética e passa a ser pensada como algébrica.

Lins e Gimenez (1997, p. 152) nos colocam que "o que caracteriza a 'verdadeira' operação aritmética é a 'sensação' de se estar 'fazendo uma conta': dois elementos são associados para 'produzir' um terceiro". Portanto, se um sujeito se depara com essa situação e ele tem essa sensação de estar fazendo uma conta, podemos concluir que ele está no domínio da aritmética. Todavia, não é o fato da expressão estar na linguagem numérica, formada essencialmente por símbolos utilizados na aritmética, que ela se caracteriza como uma expressão aritmética.

Exemplo 2. A expressão " $2 \mathrm{X}+3=15$ ", é álgebra ou aritmética?

Novamente, o sujeito que defende a ideia de álgebra de Booth (1995) responderá a essa questão de imediato, afirmando que se trata de álgebra, por aparecer símbolos (letras) para indicar valores desconhecidos. Porém, assim como a resposta à primeira questão, a nossa resposta para essa questão também é “depende". Depende, assim como para a primeira questão, da maneira que o sujeito entende essa expressão.

Por exemplo, se pedirmos para um aluno responder a essa equação, e ele iniciar da seguinte maneira: " $5 \mathrm{X}=15$ ", considerando o binômio " $2 \mathrm{X}+3$ " como uma expressão que não 
está terminada e que pode ser alvo de simplificação, o aluno não entende o sinal de "=" como uma relação de equivalência, mas, sim, como um símbolo operador.

Além disso, "influenciado pela sua experiência anterior em aritmética, encara o sinal de "+" como um indicador da necessidade de proceder a uma adição e obter um resultado" (PONTE; BRANCO; MATOS, 2008, p. 91), isto é, o aluno revela a "sensação" de estar fazendo uma conta, característico do domínio aritmético (LINS; GIMENEZ, 1997).

Nesse caso, essa expressão, mesmo sendo composta por símbolos essencialmente algébricos (números, sinais de operações e de igualdade e letras), para o aluno que a entende como foi colocado, não passa de uma expressão aritmética.

Entretanto, se o aluno entender o sinal de “=” dessa expressão como uma relação de equivalência (KIERAN, 1981), ou seja, perceber que " $2 X+3$ ” equivale a 15, essa expressão passa a ser entendida pelo aluno como uma expressão algébrica. Nesse caso, ele revela compreender que nessa situação o símbolo "=" está representando uma relação de equivalência, típico do domínio algébrico.

Portanto, para que essa equação seja pensada no âmbito algébrico, é necessário que o aluno a veja como uma relação de equivalência em que o " $\mathrm{X}$ " é um valor desconhecido que deve ser encontrado.

Entender a álgebra como uma maneira especial de pensar, na qual os objetos algébricos - por exemplo, uma equação - estão muito mais no pensamento do sujeito, e não apenas na representação no papel, não significa menosprezar a linguagem simbólica algébrica, pois temos plena convicção de que a álgebra, e a matemática como um todo, teve um avanço considerável a partir do momento que o homem conseguiu dominar e entender essa linguagem como a conhecemos hoje.

Entendemos que a evolução da álgebra, e, consequentemente, da álgebra escolar, se deu por meio da evolução da linguagem algébrica, uma linguagem cada vez mais concisa e simbólica, "uma linguagem matemática que, liberta das palavras, se volta para expressar o pensamento matemático" (ARAÚJO, 2008, p. 341).

Entretanto, essa evolução não aconteceu de um dia para o outro. Muito pelo contrário, a linguagem algébrica, como a conhecemos hoje, repleta de símbolos, só foi possível por conta de, ao que tudo indica, muito esforço da humanidade por séculos. Radford (2011b, p. 16-17) nos lembra que

a álgebra geralmente é vista como o domínio de uma certa linguagem simbólica de modo que, desde o começo, todos os esforços na sala de aula são feitos para que os alunos tornem-se competentes nesta linguagem. 
Historicamente, entretanto, o 'simbolismo' (em seu sentido moderno, aquele que encontramos nos livros didáticos atuais) só se tornou a força motriz do desenvolvimento algébrico no período da Renascença (isto é, mais de 30 séculos depois de as primeiras ideias algébricas terem visto a luz do dia!).

A história da matemática, e, em particular, a história da álgebra, nos revela que a linguagem algébrica passou por três grandes estágios, de uma linguagem natural, corrente, passando por uma linguagem sincopada, até chegar à forma como a conhecemos hoje em dia.

O primeiro estágio da linguagem algébrica é conhecido, como apontam Fiorentini, Miorim e Miguel (1993), como “retórico”. Nesse estágio o pensamento algébrico era expresso por meio da linguagem natural, verbal, ou seja, por meio de palavras. Araújo (2008) lembra que se buscarmos na história, esse estágio da linguagem algébrica pode ser encontrado já no ano 2000 a.C., período em que o povo egípcio sentiu necessidade da superação do número natural. É nessa época que aparecem as primeiras palavras, como, por exemplo, a palavra "aha”, que aparece no papiro de Rhind (século XVIII a.C.), para representar um número desconhecido.

Também podemos encontrar exemplos dessa forma de expressar o pensamento algébrico na álgebra da Babilônia, por volta do ano 1700 a.C. em alguns problemas encontrados em tábuas de argila, pois,

muitos textos de problemas do período Babilônio antigo mostram que a solução da equação quadrática completa não constituía dificuldade para os babilônios, [...] muitas fórmulas simples de fatoração lhe eram familiares. Não usavam letras para quantidades desconhecidas [...] palavras como "comprimento", "área" e "volume" serviam bem nesse papel (BOYER, 1974, p. 22).

O segundo estágio da linguagem algébrica é denominado de "sincopado", no qual o pensamento algébrico deixa de ser expresso só por meio de palavras. Passam a ser incorporadas abreviações e letras para representar, por exemplo, quantidades desconhecidas. Só que a utilização de abreviações e letras aconteceu após séculos, como nos coloca Araújo (2008).

Para essa pesquisadora, só com a nova visão de mundo, que surgiu no Renascimento, é que o movimento passou a fazer parte do cotidiano das pessoas e, portanto, foi necessária a criação de algo para representar essa fluência. O primeiro a propor algo sobre isso foi Diofante, que, no século III d.C., concebia o número como um dos elementos fundamentais do pensamento matemático. Ele é quem, pela primeira vez, utiliza letras para representar a 
"fluência", além de ser o responsável por determinar regras para abreviar potências, relações e operações.

O terceiro estágio da linguagem algébrica é o "simbólico". Esse período tem como um dos primeiros e maior representante François Viète (1540 - 1603). É esse matemático que, pela primeira vez, se vale de símbolos para representar quantidades desconhecidas. Ele utilizava "vogais para representar uma quantidade supostamente desconhecida ou indeterminada (variável), e consoantes para representar números supostamente conhecidos (parâmetros)" (ARAÚJO, 2008, p. 341).

Até o último estágio da evolução da linguagem algébrica, ou seja, até Viète, "o símbolo é utilizado apenas para representar quantidades desconhecidas em uma equação, isto é, para representar genericamente uma quantidade determinada, ainda que provisoriamente desconhecida" (FIORENTINI; MIORIM; MIGUEL, 1993). Para se chegar a essa nova maneira de expressar o pensar algebricamente, desde os primeiros registros algébricos, no estágio retórico, até o início da álgebra simbólica, no século XVI d.C., se passaram trinta e quatro séculos ou cerca de três mil e quatrocentos anos.

Verificamos, portanto, que a linguagem simbólica algébrica, tal como a utilizamos hoje, não foi desenvolvida de forma simples e rápida. Essa forma sintética de representar uma maneira particular de pensar, o pensar algébrico, levou séculos para ser desenvolvida. Entretanto, essa informação muitas vezes não é levada em consideração quando se fala no ensino da álgebra na educação básica, em que se espera que o aluno se torne proficiente nessa linguagem em um curto espaço de tempo.

Por outro lado, pesquisas apontam que a supervalorização da linguagem simbólica algébrica em situações de ensino não garante uma compreensão, por parte dos estudantes, dessa linguagem, muito menos do que ela representa. Essa forma de trabalhar a álgebra escolar a torna, muitas vezes, sem sentido, descontextualizada e mecânica (KIERAN, 1992; PONTE; BRANCO; MATOS, 2008).

É diante desse cenário que pretendemos refletir a partir de então sobre duas vertentes da álgebra escolar. Uma voltada para a supervalorização da linguagem e outra cujo foco é o desenvolvimento do pensamento algébrico, pois acreditamos que o ensino de álgebra pode ter esses dois enfoques, dependendo das escolhas feitas pelo professor.

\section{Álgebra escolar com ênfase na linguagem}

$\mathrm{Na}$ escola, o ensino de álgebra quase sempre foi voltado para a manipulação de símbolos no papel, sem sentido, ou na resolução, por meio de técnicas, de equações, como a 
técnica "muda de lado muda de sinal". Esse ensino mecânico dificilmente possibilita ao aluno construir um significado para o que está fazendo. Ele repete apenas o que o professor escreve no quadro, seguindo os modelos. Essa forma de ensinar a álgebra, essencialmente mecânica, voltada para a manipulação e o transformismo algébrico ${ }^{2}$, leva o aluno a memorizar procedimentos sem compreender o que está fazendo e nem como utilizar o que está sendo estudado em outras situações (KIERAN, 1992).

No Brasil, durante muito tempo, o ensino de álgebra foi voltado essencialmente para a manipulação mecânica de símbolos sem sentido (MIGUEL; FIORENTINI; MIORIM, 1992; ARAÚJO, 2008), apesar de pesquisadores em educação matemática e orientações curriculares, como os Parâmetros Curriculares Nacionais de Matemática (BRASIL, 1998) do final dos anos 1990, indicarem que o ensino mecânico, no qual a ênfase se encontra na linguagem simbólica algébrica, não é suficiente para que os alunos aprendam de forma significativa os conceitos algébricos.

Ainda hoje encontramos, em muitas escolas, essa forma de ensinar. Araújo (2008, p. 338-339) lembra que o "pensar algébrico ainda não faz parte de muitos processos de aprendizagem que ocorrem na escola". Para essa pesquisadora, o ensino de álgebra nas escolas brasileiras ainda está voltado muito mais para a manipulação de símbolos, para o transformismo algébrico.

Em uma pesquisa, que buscou traçar um breve caminho histórico do ensino de álgebra no Brasil, Miguel, Fiorentini e Miorim (1992) perceberam que durante muito tempo as pesquisas em educação matemática não se preocupavam com o ensino desse campo de conhecimento matemático. Ressaltam que a forma como boa parte dos professores ainda ensina a álgebra, "de forma mecânica e automatizada, dissociada de qualquer significado social e lógico, enfatizando simplesmente a memorização e a manipulação de regras, macetes, símbolos e expressões" (p. 40), quase da mesma forma como ocorria há várias décadas, indica que o seu ensino não tem, portanto, recebido a devida atenção.

Apesar de esse artigo ter sido escrito no início da década de noventa, percebemos que o cenário em relação ao ensino de álgebra no Brasil não está muito diferente nos dias de hoje (ARAÚJO, 2008), mesmo com o aumento do número de estudos nessa área.

Castro (2003, p. 6) lembra que o ensino de álgebra pouco mudou nas últimas décadas, tendo em vista que "o ensino da álgebra ainda está bastante referido à pedagogia tradicional baseada na sequência: definição - exemplos - aplicações”. Ainda segundo essa pesquisadora,

\footnotetext{
${ }^{2}$ Estamos considerando transformismo algébrico como a manipulação de expressões simbólicas a partir de determinadas regras.
} 
os alunos, em geral, terminam o ensino fundamental com bastante "dificuldade em dar significado para as atividades [algébricas] que lhes são propostas, na maioria das vezes adotando um comportamento de meros repetidores de procedimentos que o professor utiliza no desenvolvimento do tema" (2003, p. 6).

Talvez esse hábito voltado para o transformismo algébrico seja herança das práticas tradicionais propostas e praticadas desde o início da formalização desse campo de conhecimento nos ambientes escolares brasileiros, como nos colocam Miguel, Fiorentini e Miorim (1992).

Esses autores dividem, em um texto de 1992, a trajetória da álgebra escolar em três momentos - "antes do movimento da matemática moderna", "durante o movimento da matemática moderna" e "depois do movimento da matemática moderna". Em outro artigo, os mesmos autores tentam caracterizar as fases do ensino da álgebra no Brasil dividindo-o em três concepções de educação algébrica, a "linguístico-pragmática", a "fundamentalistaestrutural” e a "fundamentalista-analógica” (FIORENTINI; MIORIM, MIGUEL, 1993).

A primeira concepção de educação algébrica colocada por esses autores, a "linguístico-pragmática", corresponde ao período histórico antes do movimento da matemática moderna (MMM), iniciada com a Carta Régia de 19 de agosto de 1799, documento que legaliza o ensino desse campo de conhecimento matemático junto com a aritmética, a geometria e a trigonometria. Nesse período, o ensino de matemática era organizado em campos separados, em que o ensino da álgebra sucedia o ensino da aritmética e antecedia o de geometria. Essa forma de se trabalhar a matemática na escola prevalece durante muito tempo, pois, mesmo com a Reforma Francisco Campos, em 1931, a qual assume pela primeira vez a denominação "matemática" para designar o ensino de aritmética, álgebra, geometria e trigonometria, o ensino da matemática permanecia em compartimentos estanques, nos quais se trabalhavam os campos da matemática de forma isolada.

Na concepção linguístico-pragmática prevalece, segundo os autores,

a crença de que a aquisição, ainda que mecânica, das técnicas requeridas pelo ‘transformismo algébrico' seria necessária e suficiente para que o aluno adquirisse a capacidade de resolver problemas, ainda que esses problemas fossem, quase sempre, artificiais, no sentido de que não era a natureza e relevância deles que determinavam os conteúdos algébricos a serem aprendidos, mas a forma como 'fabricar' um problema para cuja solução tais e tais tópicos, tidos como indispensáveis, deveriam ser utilizados (FIORENTINI; MIORIM; MIGUEL, 1993, p. 83-84). 
Essa forma de se ensinar a álgebra tinha, quase sempre, uma sequência de tópicos que partia do estudo de expressões e de suas operações, até chegar às equações, finalizando com a resolução de problemas, não muito diferente do que acontece nos dias de hoje. Para Fiorentini, Fernandes e Cristóvão (2005, p. 3), “o papel do ensino da álgebra era fornecer um instrumental técnico (superior ao da aritmética) para a resolução de equações ou de problemas equacionáveis".

Na segunda concepção de educação algébrica, a "fundamentalista-estrutural", que se intensifica durante o movimento da matemática moderna, o ensino de álgebra perde o seu papel pragmático e se volta para "os aspectos lógico-estruturais dos conteúdos e a precisão da linguagem" (ARAÚJO, 2008, p. 333). Durante esse período, a álgebra assume um lugar de destaque na escola, passando a desempenhar o papel de "fundamentador dos vários campos da matemática escolar" (FIORENTINI; MIORIM; MIGUEL, 1993, p. 84).

Esse período, que se inicia nos anos de 1960, é fortemente lembrado até hoje pela introdução da teoria dos conjuntos na educação básica e pela "adoção de um certo formalismo na linguagem e a valorização das estruturas algébricas" (BÚRIGO, 2010, p. 278). Nessa época, o ensino de álgebra é voltado fortemente para a valorização da linguagem simbólica e de cálculos algébricos.

Portanto, assim como a primeira concepção de educação algébrica, a "linguísticopragmática", a segunda, a "fundamentalista-estrutural" também está voltada muito mais para o ensino mecânico e automatizado. A mudança essencial da primeira concepção em relação à segunda é que essa última perde o caráter pragmático, útil para resolver problemas, passando a ter como foco a resolução de equações e a simplificação de expressões algébricas.

Com as críticas ao movimento da matemática moderna, que entrou em declínio na metade da década de 70, começam a aparecer preocupações para tentar corrigir os excessos cometidos durante esse período, como nos coloca Araújo (2008). É após o MMM que aparece a terceira concepção de educação algébrica no Brasil, a "fundamentalista-analógica".

Essa nova concepção de educação algébrica tenta realizar uma síntese entre as duas concepções anteriores, tendo em vista que "procura, por um lado, recuperar o valor instrumental da álgebra e, por outro, manter o caráter fundamentalista - só que não mais de forma lógico-estrutural - de justificação das passagens presentes no transformismo algébrico" (FIORENTINI; MIORIM; MIGUEL, 1993, p. 84).

A diferença entre essa concepção e as primeiras é que, nessa última, as justificações dos transformismos algébricos são realizadas "não com base nas propriedades estruturais, mas, sim, por meio do uso de modelos analógicos geométricos (blocos de madeira ou mesmo 
figuras geométricas) ou físicos (como a balança) que visualizam ou justificam as passagens do transformismo algébrico" (FIORENTINI; FERNANDES; CRISTOVÃO, 2005, p. 4).

Essa nova forma de ensinar a álgebra na educação básica defendia a ideia de que a utilização de materiais concretos, como blocos geométricos, tornando assim visível certas identidades algébricas, seria "didaticamente superior a qualquer forma de abordagem estritamente lógico-simbólica" (FIORENTINI; MIORIM; MIGUEL, 1993, p. 84). Entretanto, essa ideia não deixaria de lado a abordagem simbólico-formal das outras concepções, acreditava-se simplesmente que essa etapa, geométrico-visual, poderia compor um estágio intermediário e/ou paralelo à abordagem simbólico-formal.

Apesar de essas três fases do ensino da álgebra acontecerem de forma bem definida, a primeira antes do movimento da matemática moderna, a segunda durante e a terceira depois desse movimento, percebemos que em ambas as fases a ênfase era muito mais na linguagem simbólica algébrica, no transformismo algébrico, em tópicos descontextualizados e estáticos necessários à resolução de alguns problemas artificiais, em detrimento da construção de sentido para os objetos estudados, isto é, não se tinha nenhuma preocupação com o desenvolvimento do pensamento algébrico (FIORENTINI; MIORIM; MIGUEL, 1993).

Verificamos, portanto, que desde o início do ensino da álgebra nas escolas brasileiras, e até o final dos anos de 1980 e início dos anos de 1990, a ênfase estava no ensino de uma linguagem simbólica algébrica já constituída. Só a partir do fracasso do MMM é que se começa a discutir que essa maneira de ensinar álgebra, voltada essencialmente para a linguagem e técnicas sem sentido, não atende ao anseio da escola e da sociedade de uma forma geral.

Os primeiros textos que começam a refletir sobre uma nova maneira de se pensar o ensino de álgebra, no qual o foco deixa de ser a manipulação mecânica e passa a ser o desenvolvimento do pensamento algébrico e de sua linguagem, começam a ser publicados no início dos anos 1990. Temos, como exemplos, os textos de Fiorentini, Miorim e Miguel (1993) e Kieran (1992). Esses pesquisadores começam a discutir uma nova maneira de pensar o ensino de álgebra, na qual o mais importante é a construção do significado para os objetos algébricos estudados por meio do desenvolvimento do pensamento algébrico. É essa nova maneira de pensar o ensino de álgebra que iremos discutir no tópico a seguir. 


\section{Álgebra escolar com ênfase no pensamento algébrico}

Durante muito tempo se acreditava que o ensino de álgebra, como foi discutido anteriormente, deveria estar voltado essencialmente para a manipulação mecânica de símbolos no papel, prevalecendo, essencialmente, o transformismo algébrico.

Segundo pesquisadores como Miguel, Fiorentini e Miorim (1992), os estudos em educação matemática não se preocupavam, até então - final da década de 80 - em investigar sobre o ensino de álgebra. Esses pesquisadores lembram que dentre as mais de 150 pesquisas, entre teses e dissertações em educação matemática produzidas no Brasil entre 1972 e 1990, nenhuma tinha como objeto de estudo a álgebra escolar.

Só a partir do final dos anos 1980 e início dos anos 1990 é que os pesquisadores em educação matemática começam a se preocupar com o ensino e a aprendizagem da álgebra, período em que começam a aparecer as primeiras pesquisas focadas no "modo como os alunos desenvolvem a sua compreensão de conceitos e procedimentos algébrico" (CYRINO; OLIVEIRA, 2011, p. 100). Lins (1992), Brito Lima (1996), Lessa (1996, 2005), Kaput, (1999, 2008), Kieran (1992, 2007), Fiorentini, Miorim e Miguel (1993), Arcavi (2005), Blanton e Kaput (2005), Radford (2009, 2011a, 2011b), Almeida (2016) são exemplos de pesquisadores que buscam, em suas pesquisas, entender como os alunos constroem o significado dos objetos e processos algébricos.

Para a maior parte desses pesquisadores, o centro da aprendizagem da álgebra deve ser o pensamento algébrico ${ }^{3}$. Relatam ainda que o ensino voltado para a manipulação de técnicas e de símbolos sem sentido no papel, em que prevalece o transformismo algébrico, não é suficiente. Não possibilita ao estudante entender a álgebra como deveria. O ensino de álgebra na educação básica, começando desde os anos iniciais até o ensino médio, deve estar voltado muito mais para a construção de significado e o desenvolvimento do pensamento algébrico, em detrimento da manipulação da linguagem simbólica algébrica. Para esses autores, o estudante aprenderá de forma significativa os objetos algébricos se no cerne do ensino da álgebra estiver o pensamento algébrico.

Pode parecer estranho falar em ensino de álgebra nos anos iniciais do ensino fundamental, uma vez que, no Brasil, tradicionalmente o ensino desse campo da matemática começa a partir do $7^{\circ}$ ano do ensino fundamental. Porém, pesquisadores vêm demonstrando

\footnotetext{
3 Adotaremos nesse artigo pensamento algébrico como a capacidade de analisar e estabelecer relações; de expressar ou explicar a estrutura de um problema, ou seja, construir um modelo matemático (modelar); de generalizar; de operar com o desconhecido como se fosse conhecido; e de produzir significado para a linguagem e os objetos algébricos. Mais sobre essa caracterização é encontrado em Almeida (2016).
} 
que é possível, sim, iniciar o estudo da álgebra desde os anos iniciais (SCHLIEMANN; CARRAHER; BRIZUELA, 2006; BLANTON; KAPUT, 2005; CARRAHER; MARTINEZ; SCHLIEMANN, 2008). Porém, vale ressaltar que

trabalhar com álgebra nos anos iniciais não implica introduzir a notação convencional, como por exemplo, é trabalhada no sétimo ano. Mas, pelo contrário, trabalhar com a álgebra nos anos iniciais é suscitar uma abordagem em sala de aula, na qual os estudantes tenham oportunidades de refletirem e construírem significados para relações matemáticas e conceitos algébricos, utilizando suas representações intuitivas de modo que aos poucos vão aprendendo a estabelecer representações convencionais, bem como a formular generalizações fazendo uso da notação algébrica (SILVA; SAVIOLI, 2012, p. 141).

Continuando, Araújo (2008) lembra que o ensino de álgebra deve ser focado em atividades que levem as crianças a construírem significado para aquilo que estão aprendendo. Para essa pesquisadora,

se não se introduzir a álgebra de maneira significativa, conectando os novos conhecimentos aos conhecimentos prévios que os alunos já possuem, se aos objetos algébricos não se associar nenhum sentido, se a aprendizagem da álgebra for centrada na manipulação de expressões simbólicas a partir de regras que se referem a objetos abstratos, muito cedo os alunos encontrarão dificuldades nos cálculos algébricos e passarão a apresentar uma atitude negativa em relação à aprendizagem matemática, que para muitos fica desprovida de significação (2008, p. 336-337).

Essa pesquisadora lembra ainda que para ocorrerem as mudanças necessárias para um ensino de álgebra significativo, no qual os estudantes entendam o sentido dos objetos algébricos estudados, "é preciso que se contemple além dos aspectos formais, a construção do pensamento algébrico" (2008, p. 338, grifo nosso). Assim como essa pesquisadora, Lins (1992) defende a ideia de que pensar algebricamente é uma forma de construir significado para álgebra e sua linguagem. Nesse sentido, entendemos que o pensamento algébrico deve ser o centro do ensino da álgebra. Defendemos a ideia de que os alunos constroem significado para os objetos algébricos quando são levados a desenvolverem essa forma especial de pensar.

Porém, acreditamos também que não exista uma ordem hierárquica entre esses fenômenos, ou seja, o aluno não desenvolve primeiro o pensamento algébrico para só depois construir significado para a álgebra e sua linguagem. Pensamos que isso ocorre de forma concomitante, isto é, o aluno desenvolve o pensar algebricamente e, consequentemente, constrói significado para álgebra e sua linguagem e, quanto mais significado da álgebra e de sua linguagem é construído pelo aluno, mais ele desenvolve o pensamento algébrico. 
Entretanto, quando falamos em construir significado para a álgebra e sua linguagem, não nos referimos, impreterivelmente, que o aluno está pensando algebricamente quando constrói o significado de um objeto algébrico em linguagem simbólica algébrica. Por exemplo, o aluno pode pensar algebricamente quando percebe as relações existentes entre as operações com números naturais, identificando suas propriedades, como a comutatividade, sem, necessariamente, representá-las em uma linguagem simbólica, ou seja, $(\mathrm{a}+\mathrm{b})=(\mathrm{b}+\mathrm{a}), \forall \mathrm{a} e \mathrm{~b} \in \mathrm{IN}$.

Compartilhamos, também, das ideias colocadas por Fiorentini, Miorim e Miguel (1993), Arcavi (2005) e Araújo (2008), quando defendem que não devemos apresentar aos alunos uma nova linguagem, no caso a algébrica, sem lhe dar sentido, sem que não se tenha a necessidade de utilizá-la. Devemos ter consciência de que "a linguagem é, pelo menos a princípio, a expressão de um pensamento" (ARAÚJO, 2008, p. 338).

Pesquisas, como as de Fiorentini, Fernandes e Cristovão (2005), Radford (2009), Oliveira e Câmara (2011), Silva e Savioli (2012) e Almeida (2016), revelam que os estudantes não precisam, necessariamente, dominar uma linguagem simbólica algébrica para desenvolver aspectos referentes ao pensamento algébrico. Esses pesquisadores perceberam, em seus estudos, que algumas crianças têm condições de lidar e de desenvolver aspectos relacionados ao pensamento algébrico antes de serem apresentadas a uma linguagem simbólica algébrica. Diante disso, acreditamos que podemos trabalhar com alunos da educação básica tarefas que potencializem o pensar algebricamente, sem que os estudantes tenham, ainda, domínio da linguagem simbólica algébrica.

Ponte, Branco e Matos (2008), em uma pesquisa que teve por objetivo analisar os erros e as dificuldades mais comuns dos alunos no trabalho com expressões algébricas e na resolução de equações polinomiais do primeiro grau, concluíram que o ensino e a aprendizagem da álgebra devem visar a compreensão dos seus conceitos fundamentais. "Para isso deve dar-se atenção ao desenvolvimento do pensamento algébrico, nas suas diversas vertentes, permitindo aos alunos a elaboração de raciocínios cada vez mais abstratos e complexos" (2008, p. 95).

Canavarro (2007) é outra pesquisadora que defende a inclusão de atividades que contribuam para o desenvolvimento do pensamento algébrico no currículo da educação básica desde os primeiros anos de escolaridade. Para ela, a inclusão de atividades que potencializem o desenvolvimento do pensamento algébrico no currículo de matemática "tem a ver com o seu potencial para dar unidade e sentido à matemática escolar desde o seu início, pela natureza do 
próprio pensamento algébrico" (2007, p. 91). Outro pesquisador que defende essa ideia é Kaput (1999). Para ele, o ensino com a finalidade de desenvolver o pensamento algébrico potencializa uma aprendizagem ativa que valoriza a construção de significado e a compreensão dos objetos estudados.

Percebemos, portanto, que existe um consenso entre os pesquisadores contemporâneos em educação matemática, principalmente entre os que pesquisam sobre o ensino da álgebra na educação básica, ao defenderem que o ensino de álgebra não pode ter sua ênfase na manipulação de símbolos, no transformismo algébrico, em que o foco é essencialmente a linguagem simbólica algébrica.

Diante disso, acreditamos que o ensino de álgebra deve estar voltado, principalmente, para a construção de significado dos objetos algébricos. Os estudantes devem compreender o que a linguagem simbólica algébrica significa e, para que isso aconteça, é de comum acordo entre pesquisadores que o ensino da álgebra deve estar voltado para o desenvolvimento do pensamento algébrico. Não basta olhar os símbolos. É necessário olhar por meio dos símbolos. É primordial entender o que cada símbolo significa.

\section{Considerações finais}

Podemos verificar, portanto, que na atualidade ainda temos duas concepções de álgebra escolar, uma fruto da herança das práticas tradicionais, implementadas e defendidas desde o início da escola formal no Brasil, a qual entende a álgebra escolar como uma linguagem específica utilizada para representar valores, principalmente desconhecidos. Quando defendemos essa concepção de álgebra escolar, praticamos o ensino com foco na linguagem algébrica, voltado, muitas vezes, para a manipulação mecânica de expressões algébricas e para o uso de técnicas para a solução de equações, como a "muda de lado muda de sinal". Prevalece, consequentemente, o transformismo algébrico. A linguagem algébrica é apresentada de imediato aos alunos, não levando em consideração, por exemplo, o que indica a história desse campo da matemática, a qual revela que essa linguagem concisa e cheia de símbolos levou séculos até chegar no formato que a conhecemos hoje.

A outra concepção de algébrica escolar a entende como uma forma peculiar de pensar, deixando de ser apenas um amontoado de regras vazias para a manipulação de expressões, muitas vezes sem sentido, para ser uma forma de pensamento acerca se determinadas situações matemáticas. Quando assumimos essa concepção de álgebra escolar, passamos a adotar um ensino com foco no desenvolvimento do pensamento algébrico. E, assumir esse foco é pensar em situações que levem os alunos a percorrer o caminho evolutivo da álgebra. 
É, de início, levá-los a perceber que as estratégias aritméticas são cansativas, ou não dão conta de resolver determinados problemas de estruturas algébricas. Nesse caso, a linguagem algébrica vai surgindo como necessária para modelar as situações propostas pelo professor, sendo utilizada com significado, em que os alunos deixam apenas de olhar para os símbolos, para olhar por meio dos símbolos, entendendo, por exemplo, o que cada símbolo significa em uma equação, em uma função ou em uma fórmula.

Por fim, ressaltamos que defender o ensino de álgebra voltado para o desenvolvimento do pensamento algébrico não significa menosprezar sua linguagem. O que defendemos é que essa linguagem deve ser trabalhada com significado; que, com o desenvolvimento do pensamento algébrico, o aluno sentirá a necessidade de representá-lo em uma linguagem cada vez mais simbólica, chegando, ao final, ao domínio dessa linguagem, porém, com significado.

\section{Referências}

ALMEIDA, J. R. Níveis de desenvolvimento do pensamento algébrico: um modelo para os problemas de partilha de quantidade. 2016. Tese (Doutorado em Ensino de Ciências e Matemática) - UFRPE, Recife, 2016.

ARAÚJO, E. A. Ensino de álgebra e formação de professores. Educação Matemática Pesquisa (Online), São Paulo, v. 10, n. 2, 2008.

ARCAVI, A. El desarrollo y el uso del sentido de los símbolos. In: CONFERÊNCIA plenária no encontro de investigação em educação matemática. Anais ... Caminha, Portugal, 2005.

BLANTON, M. L.; KAPUT, J. Characterizing a classroom practice that promotes algebraic reasoning. Journal for Research in Mathematics Education. EUA, v. 36, n. 5. 2005.

BOOTH, L. R. Dificuldades das crianças que se iniciam em álgebra. In: COXFORD, A. F.; SHULTE, A. P. (Org.). As ideias da álgebra. São Paulo: Atual, 1995.

BOYER, C. B. História da Matemática. Tradução de Elza Gomide. São Paulo: Edgar Blücher, 1974.

BRASIL. Secretaria de Educação Fundamental. Parâmetros Curriculares Nacionais: Matemática. Brasília: MEC, SEF, 1998.

BRITO LIMA, A. P. A. Desenvolvimento da representação de igualdade em crianças de $1^{\mathbf{a}} \mathbf{a}^{\mathbf{a}}$ série do $^{\mathbf{0}}$ grau. 1996. Dissertação (Mestrado em Psicologia Cognitiva) - UFPE, Recife, 1996. 
BÚRIGO, E. Z. Tradições Modernas: reconfigurações da matemática escolar nos anos 1960.

Boletim de Educação Matemática - BOLEMA (Online), v. 23, n. 35B. Rio Claro - SP, 2010.

CANAVARRO, A. P. O pensamento algébrico na aprendizagem da Matemática nos primeiros anos. Quadrante, Portugal, v. VXI, n. 2, 2007.

CARRAHER, D. W.; MARTINEZ, M. V.; SCHLIEMANN, A. Early algebra and mathematical generalization. ZDM Mathematics Education. DOI, v. 40, p. 3-22, 2008.

CASTRO, M. R. Educação algébrica e resolução de problemas. Boletim Salto para o Futuro, TV Escola. Brasília, 2003.

CYRINO, M. C. C. T.; OLIVEIRA, H. M. Pensamento Algébrico ao longo do Ensino Básico em Portugal. Boletim de Educação Matemática - BOLEMA (Online), v. 24, n. 38, Rio Claro - SP, 2011.

FIORENTINI, D.; MIORIN, M. A.; MIGUEL, A. Contribuição para um repensar... a Educação Algébrica Elementar. Pro-Posições. Campinas, v. 4, n. 1[10], 1993.

FIORENTINI, D.; FERNANDES, F. L. P.; CRISTOVÃO, E. M. Um estudo das potencialidades pedagógicas das investigações matemáticas no desenvolvimento do pensamento algébrico. In: SEMINÁRIO Luso-Brasileiro de Investigações Matemáticas no Currículo e na Formação de Professores. Anais... Lisboa, 2005.

KAPUT, J. Teaching and learning a new algebra. In: FENNEMA, E.; ROMBERG, T. A. (Eds.). Mathematics classrooms that promote understanding. Mahwah, NJ: Lawrence Erlbaum, 1999.

What is algebra? What is algebraic reasoning? In: KAPUT, J.; CARRAHER, D.; BLANTON, M. (Eds.). Algebra in the Early Grades. New York: Lawrence Erlbaum Associates, 2008.

KIERAN, C. Concepts associated with the equality symbol. Educational Studies of Mathemates. Dordercht, 1981.

The Learning and Teaching of school Algebra. In: GROWS, D. A. (ed.). Handbook of Research on Mathematics Teaching and Learning. New York: Macmillan, 1992.

The changing face of school algebra. In: ALSINA, C. Et al. (Eds.). ICME 8: Selected Lectures. Seville: S. A. E. M. Thales, 1996.

The Core of Algebra: Reflections on its Main Activities. In: STACEY, K. et al. (Eds). The Future of teaching and learning of algebra: The 12th ICMI Study. Dordrecht: Kluwer Academic Publishers, 2004. pp. 21-34. 
Developing algebraic reasoning: The role of sequenced tasks and teacher questions from the primary to the early secondary school levels. Quadrante. Portugal, v. XVI, n. 1, 2007.

LESSA, M. M. L. Balança de dois pratos e problemas verbais como ambientes didáticos para iniciação à álgebra: um estudo comparativo. 1996. Dissertação (Mestrado em Psicologia Cognitiva) - UFPE, Recife, 1996.

Aprender álgebra em sala de aula: contribuição de uma sequência didática. 2005 . Tese (Doutorado em Psicologia Cognitiva) - UFPE, Recife, 2005.

LINS, R. C. A framework for understanding what algebraic thinking is. 1992. Tese (Doctor of Philosophy) - School of Education, University of Nothingam, Nothingam, UK, 1992.

LINS, R. C.; GIMENEZ, J. Perspectivas em Aritmética e Álgebra para o século XXI. Campinas, SP: Papirus, 1997.

MIGUEL, A.; FIORENTINI, D.; MIORIM, M. A. Álgebra ou geometria: para onde pende o pendulo. Pro-Posições, Campinas, v. 3, n. 1, 1992

OLIVEIRA, I.; CÂMARA, M. Problemas de estrutura algébrica: uma análise comparativa entre as estratégias utilizadas no Brasil e no Québec. Anais da XIII Conferência Interamericana de Educação Matemática, Recife, 2011.

PONTE, J. P.; BRANCO, N.; MATOS, A. O simbolismo e o desenvolvimento do pensamento algébrico dos alunos. Educação e Matemática, Lisboa, Portugal, 2008.

RADFORD, L. Signs, gestures, meanings: Algebraic thinking from a cultural semiotic perspective. Anais do Sixth Congress of the European Society for Research in Mathematics Education. Lyon, França, 2009.

Cognição matemática: história, antropologia e epistemologia. São Paulo: Livraria da Física, 2011a.

Antes que outras incógnitas fossem inventadas: investigações didáticas acerca dos métodos e problemas da álgebra italiana medieval. In: RADFORD, L. Cognição matemática: história, antropologia e epistemologia. São Paulo: Livraria da Física, 2011 b.

SCHLIEMANN, A. D.; CARRAHER, D. W.; BRIZUELA, B. M. Bringing out the algebraic character of arithmetic: from children's ideas to classroom practice. studies in mathematical thinking and learning series. Lawrence Erlbaum Associates, 2006.

SILVA, D. P.; SAVIOLI, A. M. P. D. Caracterizações do pensamento algébrico em tarefas realizadas por estudantes do Ensino Fundamental I. Revista Eletrônica de Educação. São Carlos, SP. UFSCar, v. 6, n. 1, 2012. 
USISKIN, Z. Concepções sobre a álgebra da escola média e utilizações das variáveis. In: COXFORD, A. F.; SHULTE, A. P. (Org.). As ideias da álgebra. São Paulo: Atual, 1995. 